\title{
EM FAVOR DA TEORIA ANTROPOLÓGICA: O MANIFESTO DE GELL
}

VINÍCIUS TEIXEIRA PINTO ${ }^{1}$

UFRGS

\section{RESENHA}

GELL, Alfred. Arte e Agência: uma teoria antropológica. Trad. Jamille Pinheiro Dias. São Paulo: Ubu Editora, 2018, 400p.

Vinte anos depois de sua primeira publicação, Arte e Agência, do britânico Alfred Gell, ganha agora sua versão editada no Brasil. Trata-se de um livro com ares de obra clássica para a antropologia da arte, pois apresenta e revisita uma quantidade diversificada de exemplos oriundos tanto das artes ocidentais, as obras de Picasso, Duchamp e outros, quanto de trabalhos etnológicos variados, como nos casos do Kula ou das casas Maori. O propósito do autor é ambicioso: definir, em contraponto a alguns de seus colegas e debatedores, uma teoria geral, sumamente antropológica, da arte - nem estética nem cultural - cujo ponto de partida seja o das relações sociais.

Percebe-se facilmente que aquilo que Gell toma por teoria antropológica passa por este caminho, o das relações sociais. O próprio autor indica assumir uma noção, talvez até, estreita da antropologia. Sem meias palavras, anuncia que, "na medida em que a teoria da troca em Mauss é a 'teoria antropológica' exemplar e prototípica, teríamos de construir uma 'teoria da arte antropológica', mas que tratasse de objetos de arte, e não de prestações" (p. 35). E insiste que, ao contrário das teorias semióticas ou estéticas, sua proposta para a arte tem a obrigação de dialogar com outras perspectivas antropológicas.

É importante considerar que este livro está na esteira de uma discussão sobre estética desenvolvida no último quarto do século passado. A coletânea Key Debates in Anthropology, organizada por Tim

\footnotetext{
${ }^{1}$ Doutorando no Programa de Pós-Graduação em Antropologia Social da Universidade Federal do Rio Grande do Sul. E-mail: viniciustxp@gmail.com
} 
Ingold e dedicada a algumas questões controversas naquele momento, reserva, por exemplo, uma sessão a questionar a possibilidade de uma antropologia dedicada à estética, caso esta seja tomada enquanto uma categoria transcultural, universalizável. O debate registrado em 1993 conta com os argumentos de Howard Morphy e Jeremy Coote, que defendem a existência de uma capacidade humana para o estético, bem como de definições de beleza em outros vocabulários. Joanna Overing e Peter Gow, por oposição, destacam a particularidade e historicidade do julgamento de uma "estética pura" no Ocidente, onde o objeto de arte é apartado de sua contextualização (INGOLD et al., 1996).

Gell, que também participa do encontro, está mais próximo da linha argumentativa destes dois. Em uma publicação anterior ao debate, já sinalizava que "a estética é um ramo do discurso moral, que depende da aceitação dos artigos iniciais da fé" (GELL, [1992] 2005, p. 43). A validade do esforço antropológico dependeria, assim, de uma "atitude de indiferença resoluta" sobre o valor estético da obra de arte. Ele rejeitará, portanto, a generalização transcultural do conceito de "estética", fazendo questão de demonstrar que sua preocupação é a de oferecer uma alternativa teórica, dentro da antropologia, para 0 problema da arte.

Vale destacar que a recusa à noção de "obra de arte" é condição necessária, afinal a arbitrariedade desse termo restringiria o alcance da investigação a objetos assim definidos desde uma perspectiva institucional e excludente. Por isso, sua antropologia da arte se propõe a "explorar um domínio em que os 'objetos' se misturam às 'pessoas', dada a existência de relações sociais entre pessoas e coisas" (p. 40). Neste sentido, Arte e agência, mesmo sendo uma publicação póstuma, é capaz de atravessar esse momento de crítica aos modelos semióticos ou comunicacionais, entregando uma contribuição metodológica que, se não podemos considerar unânime ${ }^{3}$, é, sem dúvidas, peculiar. Sua novidade passa exatamente por um aparato conceitual cuja familiarização é essencial para sua compreensão, conforme detalhado no capítulo 2.

O "índice", conceito buscado em Charles Peirce, eliminaria o problema da definição apriorística do estético carregada automaticamente na ideia de "obra de arte". Esta categoria denomina a entidade material, o objeto, a coisa física passível de uma operação cognitiva denominada "abdução da agência". A abdução, ao mesmo tempo, é uma via para escapar às propostas que equivalem a arte a uma linguagem decodificável. São induções embasadas em suposições provocadas pela materialidade do índice.

E o conceito mais importante para sua antropologia da arte é

3 Não surpreende que Morphy, um dos principais alvos de Gell, tenha se mostrado bastante crítico em relação à Arte e Agência. Segundo ele, seu colega teria uma definição estreita da teoria antropológica, centrada nas relações sociais, em detrimento da estética. Além disso, a atribuição de agência a objetos seria algo que "desvia o foco da antropologia da arte dos muitos modos pelos quais a arte contribui para a ação social e para a reprodução da identidade" (MORPHY, 2011, p. 241). 
exatamente o de "agência social". Por agentes, podemos compreender quaisquer pessoas ou coisas "vistas como iniciadoras de sequências causais de um determinado tipo, ou seja, de eventos causados por atos da mente, da vontade ou da intenção, e não de uma mera concatenação de eventos físicos" (p. 45). Os agentes desencadeiam eventos a partir de si mesmos e não precisam ser necessariamente humanos. Um animal, uma escultura ou um automóvel, como exemplifica o autor, não só podem iniciar cadeias causais como ainda podem adquirir personalidade e constituir noções de pessoa daqueles que se relacionam com estes "objetos".

No modelo apresentado por Gell, há quatro termos básicos envolvidos nas relações. Tratam-se de índice, que já vimos em detalhe, de artista (aquele cuja autoria é atribuída), de destinatário (aquele de quem se espera a recepção do índice) e de protótipo (entidade idealizada no índice), cujo nexo é a arte (p. 60). A questão que se coloca é que qualquer um dos termos pode assumir agência em relação aos demais, variando de caso a caso. Em dado contexto, o índice pode ser agentivo do artista, como na arte japonesa ou nos ready-mades, em que objetos encontrados se tornam arte (p. 64). Em outras situações, o destinatário pode ser agente em relação ao índice, vide o exemplo do mecenato (p. 68) ${ }^{4}$.

A capacidade agentiva dos chamados objetos inanimados se justifica neste modelo por uma noção alargada de pessoa - tema tão caro à antropologia e principal fundamento teórico de Arte e agência. Os exemplos dados no capítulo 7 são oriundos da idolatria de imagens com o fim de pensar o animismo enquanto limite inalcançável para as explicações de ordem representacional. De antemão, rejeita-se, por insuficientes, também as explicações de causalidade das ciências naturais que tendem a ser deterministas sobre a ideia de ação (p. 190195). Assim, a agência deve ser entendida a partir do próprio índice - no entanto, em relação sociológica, isto é, em relação a pessoas (p. 155159).

A questão é melhor resolvida no capítulo de conclusão do livro, através das ideias de "objetos distribuídos" e de "extensão da mente". A premissa básica é a de que não é tão simples delimitar os lados de "dentro" e de "fora" da mente humana, afinal há motivos para acreditar que processos cognitivos são ainda coletivos, de ordem externa ( $p$. 322). E, que o que se compreende por "pessoa", no sentido antropológico, "abrange também todos os objetos ou acontecimentos de um dado meio a partir do qual a agência ou a personitude podem ser inferidas por abdução" (p. 323). Mais do que isso, objetos, como

\footnotetext{
4 No terceiro capítulo, Gell apresenta um quadro das combinações possíveis. No capítulo seguinte, afirma existirem 36 fórmulas oriundas em que o índice é agente primário ou paciente primário. Segundo ele, a "teoria do tipo que está sendo desenvolvido aqui consiste basicamente em um dispositivo para ordenar e classificar o material empírico, e não em oferecer generalizações ou previsões normativas resultantes" (p. 61). Ou seja, os esquemas formulados não têm por objetivo produzir regras, normas, tendências sobre as relações de ordem agente/paciente.
} 
monumentos e túmulos, seriam possibilidades de estender a pessoa para além do tempo biológico.

Tomemos o exemplo das esculturas malangan, que Gell retira das pesquisas de Susanne Küchler na Nova Irlanda, portanto, no contexto da Melanésia. Enquanto peças de museu, são objetos que se tornaram exemplares da arte etnográfica. No contexto de sua fabricação, no entanto, estas esculturas - entendidas aqui enquanto índices - possuem uma vida breve que se reduz à duração cerimonial, pois seu "propósito [...] é oferecer um 'corpo' ou, mais precisamente, uma 'pele' para uma pessoa de destaque que acabou de falecer e cuja agência, após a morte, permanece em um estado de dispersão" (p. 327). Considerando a noção de pessoa melanésia, que por vezes vem sendo descrita como "fractal" ou "distribuída", é possível considerar o malangan como "um tipo de corpo que acumula, como se fosse uma bateria carregada, a energia potencial do falecido, dispersa no mundo dos vivos", ao mesmo tempo em que a sociedade se ajusta "ao subtrair o falecido de participar ativamente na vida política e produtiva", dado que "[suas] hortas e plantações [...] ainda são produtivas; seus bens são geridos por diferentes parceiros de troca; suas casas ainda estão de pé; seus maridos ou esposas continuam casados com eles, e assim por diante" (p. 327).

Encerrado o tempo cerimonial, o malangan, este índice que foi um repositório material da vida do falecido, é descartado ou destruído. A necessidade de sua existência deriva, não de uma propriedade puramente estética ou representacional do mundo, mas, diferentemente disso, de sua capacidade agentiva ao desencadear relações.

Para Gell, abordar os objetos de arte por um viés hermenêutico, enquanto uma via de acesso para compreensão de dado sistema cultural $^{5}$, é uma forma de ignorar estas relações sociais e este caráter agentivo dos índices materiais. Enquanto sistema tecnológico, pode-se dizer que a arte faz parte de processos cognitivos, sendo constitutiva da noção de pessoa. As casas maori, por exemplo, têm seus atributos estilísticos e arquitetônicos. Mas estes atributos não são detalhes supérfluos. Estas mesmas casas condicionam espacialidades, temporalidades e usos, através da distribuição de seus cômodos, "são um corpo para outro corpo. [...] Entrar em uma casa é entrar em uma mente, uma inteligência sensível" (p. 363).

Arte e agência é certamente uma obra ousada, cujo diálogo mais aprofundado no Brasil parece ter sido, até aqui, com a etnologia ameríndia, especialmente pelo intermédio de Els Lagrou. A autora de $A$ fluidez da forma aproveita a contribuição conceitual de Gell para discutir a agência de objetos, principalmente desenhos, ao mesmo tempo em que pensa corpo e noção de pessoa na Amazônia (LAGROU, 2007), em diálogo íntimo com várias das questões gestadas no contexto etnográfico da Melanésia. Esta tradução para o português deve ajudar a

5 E.g. Geertz (1976). 
impulsionar outras leituras, outras abordagens.

Finalmente, é preciso dizer que o texto de Gell oferece uma série de fórmulas complexas que deveriam permitir categorizar arranjos variáveis de agentes e pacientes. Isso, quem sabe, é também aquilo que deixa a impressão de que algumas de suas respostas são insuficientes. É verdade que a proposta contribui para pensar a agência nos objetos, sob a forma de "índice". No entanto, também é verdade que esta agência é sempre de segunda ordem, o que nos aparece enquanto indício de uma noção de agência demasiado euro-americana e abre uma brecha para a crítica a partir da virada ontológica ${ }^{6}$. Em todo caso, é preciso considerar Arte e Agência por sua contribuição aos debates do fim de século, quando suas principais interlocuções eram as teorias que equivaliam a arte à estética. Por isso, esta nova publicação nos reporta àquele momento - que foi o chamado de Gell para uma teoria antropológica, um legítimo manifesto em favor de uma teoria antropológica da arte.

\section{Referências bibliográficas}

GEERTZ, Clifford. Art as a cultural system. MLN, Baltimore, v. 91, n. 6, p. 1473-1499, dez. 1976.

GELL, Alfred. A tecnologia do encanto e o encanto da tecnologia. Concinnitas, Rio de Janeiro, v. 1, n. 8, p. 41-63, [1992] jul. 2005.

Arte e agência: uma teoria antropológica. São Paulo: Ubu Editora, 2018.

HENARE, Amiria; HOLBRAAD, Martin; WASTELL, Sari (Orgs.). Thinking through things: theorizing artefacts ethnographically. New York: Routledge, 2007.

INGOLD, Tim (Org.). Key debates in anthropology. London; New York: Routledge, 1996.

LAGROU, Els. A fluidez da forma: arte, alteridade e agência em uma sociedade amazônica (Kaxinawa, Acre). Rio de Janeiro: Topbooks, 2007.

MORPHY, Howard. Arte como um modo de ação: alguns problemas com Art and Agency de Gell. Proa: Revista de Antropologia e Arte, Campinas, v. 1, n. 3, p. 225-247, 2011.

6 Thinking through things, coletânea de Henare, Holbraad e Wastell, considera e tensiona alguns dos argumentos de Arte e agência. O texto de James Leach, por exemplo, pondera que a manutenção da separação entre "pessoas" e "coisas" assevera, ao segundo termo, uma agência necessariamente derivada em relação ao primeiro (HENARE et al., 2007, p. 17). 
Espaço Ameríndio

Recebido em: 09/12/2018* Aprovado em: 18/03/2019* Publicado em: 27/06/2019 